\title{
American Corporate Capitalism's Effect on Adolescent Psychology
}

\author{
Abigail Weaver ${ }^{1}$ and Diane Patterson ${ }^{1}$
}

${ }^{1}$ Northridge High School, Greeley, CO, USA

\section{ABSTRACT}

The purpose of this study was to identify how the cultural norms of American Corporate Capitalism affect the psychological behaviors of American adolescents between the ages of thirteen and seventeen. Prior research shows a considerable correlation between consumerist habits and youth; however, studies failed to recognize the strategies corporations utilize to influence such behaviors in children. Data was collected through a content and meta-analysis in which multiple sources were applied to the focus of the current research based on the importance of the topics presented. Due to the nature of my research, I focused on the results of studies revolving around mental health, selfefficacy, materialism, consumerism, and American Corporate Capitalism. Initial results showed a considerable link between the level of consumerism to a child's wellbeing as well as how businesses utilize psychological tactics to adhere to those specific groups. The persuasion tactics utilized have been instilled in societal culture so thoroughly to where it nearly reflects a person's self-worth. Therefore, the conclusion can be made that the culture instituted through the system of American Corporate Capitalism has created negative behaviors within the youth of America. However, this is limited to describing how it correlates with psychological behaviors and does not focus on how adolescents choose to address it, whether through avoidance or acceptance. Future research should focus on how children interact with the persuasion tactics of big corporations; what their neurological responses are that could be curtailed to avoid such negative implications.

\section{Introduction}

American corporations assert themselves as having their own cultures within society's overall way of life. Businesses have created shortcuts to boost themselves economically like that of Amazon, Novo Nordick, and the Carlyle Group. In fact, it has become so ingrained in our society that consumers feel obligated to give their money back to these markets and their abrasive status quos. The ethical notions inside businesses have constantly been overhauled by lawsuits, loopholes, and the workforce itself. It stands to reason that often with the mounting success brought to the United States, many ignore the capitalistic qualities of such competitive cultures. After all, the Clayton Act (1890) was used to hold limits on large companies like those involved with oil and railroads but now as companies become more complicated, these antitrust laws are harder to enforce. Due to this, Amazon-for example-has 51.8\% of the United States market shares which forces corporations like the Central Intelligence Agency and state departments to use their web services. Having this type of control over political proceedings even at the lowest absolute threshold poses a significant influence over the average citizens.

At the expense of the workforce, free market capitalism has grown to accentuate the lower and higher income classes while effectively squeezing a struggling middle class. This is most widely regarded as Consumer Hourglass Theory (Collins, 2015). As of 2015, more than 25 million middle income families live paycheck to paycheck with a median salary of $\$ 41,000$ and assets at $\$ 41,000$ (Collins, 2015). This in itself is due to businesses having been given full control over their operations and regulations by the government. 
While much research has gone into the detrimental impact of American Corporate Capitalism (ACC) on families economically, few have focused solely on how it's affected children ideologically. Studies have suggested that the relationship between corporate ideologies and institutions has caused a shift in the psychological wellbeing and practices of the average citizen. The psychological behaviors instilled in parents who interact with ACC greatly adds to the intergenerational transfer (p. 93 Polacheck; 1874b, p. 433 Leibowitz) of such behaviors to their children. With growing awareness among teens, questions regarding the effectiveness of businesses have risen. Yet, there are limited sources detailing the psychological effects of corporate advertisement compared to those of younger children. Children of this age are considered in a general observation as opposed to being the sole focus of many studies. Thereby this research aims to identify how the psychology of ACC has affected the psychology of children ages thirteen to seventeen in the past decade.

The following paper will use a combination of content and meta analyses to address this concern. Many studies have been published on topics of capitalism's psychological and economic impact on average Americans. In addition, there have been multiple news and media outlets publishing their discoveries of corporate scandals which will be used also. They showcase the consequences, both positive and negative, of America's growing business culture. An entire empire that's been created on how best to entice the consumer through advertisements and cognitive proceedings. Increasingly effective, it has become a belief that by spending money, they are exercising their civic duty as Americans. Thereby, the following will review the gathered resources and identify crucial inferences based on such proven data. These deductions will focus on the impact in relation to adolescent youth.

The corporate playbook remains an enigma to the average citizen and causes them to adjust to these practices blindly. However, with Generation Z's cultural shifts compared to previous age groups, practices of ACC have to be reviewed for effectiveness. By tweaking behaviors to match consumerist habits, it can be inferred that most of these customs are detrimental to the average child. Shalom Schwartz, a social psychologist, had a six stage theory of ACC which, when paired with Erikson's Development Theory, shows a significant potential for damaging a child's growth. Schwartz believed in stages of Mastery v. Harmony, Hierarchy v. Egalitarianism, and Embeddedness v. Intellectual Autonomy to be discussed in more depth later on. But when paired to Erikson's stages of Industry v. Inferiority, Generativity v. Stagnation, and Ego Integrity v. Despair (as most basic examples), it holds the potential to create inward conflict and disruptiveness in children. These theories, as well as a majority of the data collected, fall in line with the humanistic perspective of modern psychology.

Now that isn't to say that businesses are assuredly damaging children. Many companies have beneficial use of Schwartz's theory and the cultures they create within their walls. However, more should be focused on those businesses that don't have balanced social influences. By addressing them, it can allow for more information on just how seriously ACC affects adolescents at this time.

\section{Literature Review}

As denoted by the professor of moral philosophy Adam Smith, the patron saint of United States Capitalism, it was the goal of many to harness the instinct of self-servitude into creating profitable economic patterns (Whybrow 2007, p. 57, Kasser, Kanner, Cohn, \& Ryan 2007, p. 3). Historically, capitalism emerged as a hegemonic movement in the late 1880s to early 1920s where supporters of a laissez-faire economy began a social movement with the Populist Party to allow for a less restrictive market, thereby ensuring safety to their status of power (Schneirov 2016, p. 563). (Durant, 2014) attributed this success to the elites who were educated in Germany, a country known for laissez-faire economics. Their private interests garnered public gain due to a belief in their legitimacy. This created a shift from democratic control over businesses to more bureaucratic oversight where state powers are dwarfed by corporations. Progressives claim it was intended to save the Constitution even as issues began to arise with ties back to the new age of a freemarket economy (p. 605).

A claim by many psychologists is that "...ACC is in fact like other social systems in that it has an ideology that organizes institutions," (Kasser et al., 2007, p. 60). There is a constant goal for material gain with a cultural shift 
from community focus to that of the individual (Whybrow 2007, p. 58, George 2014, p. 8-9). (George, 2014) set ACC into five categories of thought. Competitiveness in a free-market, growth in materialism, emphasizing consumerism, upholding the sanctity of private property, and protecting self-interest (p. 8-9). That self-interest encourages productive innovation and advancing convenience to consumers (Myers 2007, p. 45). This has been shown as products like Gain dish soap are being created to meet the demands of both the upper-middle class and lower-middle class markets (Northwestern Business Review, 2012). After coming from the dreaded time of Reaganomics and President Carter's pacifist approaches, the populus sought relief from ACC (Schneirov 2016, p. 569).

As free-market capitalism rose, so cultivated did the culture of American Corporate Capitalism become that it inflicted society in waves. Poverty, unemployment, and disease were publicly attributed to an imbalanced social order most commonly related to Carl Marx's social conflict theory. This entitled that there would always be a conflict between the wealthy elite and the lower classes for power. As businesses began to flourish with their new liberalism, those most similar to the petite bourgeoisie class melded into the proletarian class (Harris 1939, p. 328). In today's terms, these groups would be classified as middle-class store owners, independent farmers, and artisans becoming industrial workers and landowners. Harris (1939) shows how Marx has explicitly proven that while "increasing misery" within worker mentality has grown, it does not mirror that of the economy (p. 330). In this way, the economic polarization of markets caused upper and lower classes to bulge with an increased population. Yet the middle class is squeezed into disappearance, notably coined as the Consumer Hourglass Theory (Collins, 2015).

The movement caused citizen perception of self-efficacy and political involvement to be undermined by what businesses choose to project (Durant 2014, p. 619). Two notable fault lines include the lack of investment by companies within their own futures and the lack of investment in their employees. (Kinni, 2017, para. 7-8). As society became disgruntled holistically, businesses emphasized the usage of organizational psychologists in finding homeostasis between production and the workforce. (Kramer 2006, p. 293). Some companies like Herman Miller, Inc. have employed compassionate capitalism with their local ownership, engaged human resources, and the philosophies of faith and benevolence. For the workforce, having engaged workers possessing a sense of teamsmanship, and fulfillment created less turnover, higher productivity, and greater profits. Many businesses have utilized the theory of corporate social responsibility in finding ways to help society mutualistically (Myers 2007, p. 45-46; Kumar, Boesso, Batra, and Yao 2018, p. 2). The workforce is geared towards a mix of capitalism and socialism with businesses utilizing middle grounds between corporations and unions to compromise the best for production (Schneirov 2016, p. 566). In this way, working culture has adapted to where staff felt over benefitted by prosocial motivation and scored higher on emotional exhaustion than those who were under benefited (Hickey 2014, p, 84).

In fact, the growing distance between the rich and poor has the United States in first place of having the greatest income inequality of western nations (Myers 2007, p. 44). The country has the highest overall poverty rate in any industrialized nation on earth as it became more entrepreneurial as opposed to bureaucratic. On average, the top one percent share of total wealth went from seven to twenty-three percent from 1975 to 2014. With this comes much of the issue regarding America's socioeconomic disparity. (Collins, 2015, para. 4). So ingrained into our society, finances now influence thoughts and actions on an unconscious level as well, involving the psychoanalytical perspective of psychology. There's been a reflecting belief that possessions can be quantified to one's happiness and life satisfaction which has many creating studies attributing such hypotheses to child surveys (Sweeting, Hunt, and Bhaskar, 2012, p. 803). (Myers, 2007) noted while the economy grows, the divorce rate is twice as high, teen suicide is three times as much, violent crime excelled by four, and the prison population expanded by five (Myers, $2007 \mathrm{p}$. 43). Eighteen-year old in higher socioeconomic classes have shown higher rates of consumer-oriented views. This has led to a perception that the amount of materials relates to one's amount of success. (George 2014). In a study analysis, a correlation in America "between consumerism and psychosomatic symptoms, depression, anxiety, and lower selfesteem in 9-13-year old (Schor 2004)" demonstrated an impact of lifelong consumerist persuasion (Sweeting et al., 2011, p. 804). While studies for adults focus on possessiveness, non-generosity, and envy, those involving children identify personal happiness and social growth in relation to possessions. For what has been discovered, if an item is found to be difficult to attain it is considered prestigious and therefore bolsters one's social status. It is a consistent 
pattern of the human capital theory that argues for an intergenerational transfer of parental consumer patterns to be passed along to their kin. (Sweeting et al., 2011, Polachecks, 1989). However, studies report from the Polachecks (1989) that such a thing as Reverse Intergenerational Transfer (RIT) exists where the child's behaviors change parental consumption. Given this reason, many companies established 'Cradle-to-Grave' marketing strategies (Kramer 2006, p. 295). This entails the usage of subliminal messaging to persuade the viewer to buy an item. Psychologically this call into question the legitimacy of neuromarketing.

Kramer notes that while the American Psychological Association (APA) has a constitutional expectation to prevent nonmaleficence, the risk of child advertising has yet to be addressed. Division 23 of the APA is the Society for Consumer Psychology, focused on advertising and persuasion. One notable case was that of James Watson in the 1920s where he used his psychological background to focus commercials on the pathos of children. In a 1997 Child Development Supplement (Sweeting et al., 2011), the rise of materialism led to a rise of anxiety, fear, and depression. With this, a parent-child conflict can occur from the conflict of buying items. Such cognitive disharmony creates tension for the customer with the only viable solution to be the purchase of such materials (Kramer 2006, p. 205, Vlasceanu 2013, p. 24). However, with the theory of reverse intergenerational transfer, children have begun to make more informed decisions on prices and qualities with the more education and years of life they possess. Because of this, their communication with their parents leads to the family as a whole making similar choices (Polachecks 1989). Now, as businesses show developed fervor for communicating with the consumer, the question remains as to how this has affected the consumer's self-efficacy.

\section{Method}

\section{Participants}

With the question in mind revolving around the effects on adolescents, much of the participating sets of data used children as their subjects. Time constraints made the usage of other studies necessary while also allowing for other subjects to be considered such as middle-aged workers in regard to their emotional exhaustion in the workplace. However, those were not scrutinized to the depth that the child datasets were. The most pertinent subjects proved to be those within the United Kingdom studies compiled by Sweeting et al. in which adolescents eight to eighteen years of age were surveyed under three different scales of materialism. In total, there were 1,496 males and 1,438 females in the 2010 Scottish secondary school survey. This survey combined the three studies within one synthesized source of material displaying childhood thought patterns regarding consumerist habits. Much of what was found across the board related emotional and behavioral problems to materialistic conflicts. These patterns were applied to conclusions made after lengthy deliberation across multiple accounts of expertise regarding child psychology, American sociological behavior, and American Corporate Capitalism.

\section{Measurements}

I chose the most influential sources by identifying which articles interacted with capitalism, child behavior, and social psychology the most. These pieces were articles from Tim Kasser et al., Robert Hickey, Robert Durant, Dora and Solomon Polacheck, Jennifer M. George, Helen Sweeting et al, and Juli B. Kramer shown in the table below. They provided information on the history of American Corporate Capitalism as well as its involvement in shaping society's modern culture. For each one that gave the most in-depth analysis into these topics, the most attention was given to. The articles that provided more concrete information regarding the three prior topics found to be of more fruition in the measurement of societal impact. More specifically, "An Indirect Test of Children's Influence on Efficiencies in Parental Consumer Behavior " by Dora and Solomon Polacheck showed the most sophisticated statements with credible proof of work. These would form the basis of conclusions that were made later to ensure new statements were in 
line with the cultural rulings of American Corporate Capitalism, added with the findings from Myers (2007) and Whybrow (2007).

\section{Design}

This research dilemma can be best analyzed by a content and meta-analysis. Both strategies allowed for information from previous studies to be synthesized into application for the current research question. This allowed for more information to be gained by examining different aspects of business to child relations. Every human is naturally indoctrinated into a certain set of behavioral traits in how they interact with society. Therefore, the information received had to be applied to the theories of child psychology; which a content analysis allowed for. By comparing the cultural aspects of American corporations with the general psychosis of the adolescent population, more concrete theories were produced which tied the growth in consumerism to a growth in negative behaviors. It would also be pertinent to identify the economic impact corporations have on families with children in the observable age range. Such development can be seen from Mike Collins (2015) and S. VLĂSCEANU (2013) Though it is also important to note the mindset of the businesses as well as opposed to solely focusing on their impact on American families. This standpoint, provided by Kinni (2017), Kumar et al. (2019), and the Northwestern Business Review (2017) allows for a more balanced representation.

\section{Procedure}

By first accumulating a multitude of sources and articles regarding ACC and child materialistic behaviors, I carefully annotated each and assessed the cruciality of usage. I found research that varied from Corporate Social Responsibility and the economic disparities within the free market system, to historical social movements, and child adjustment periods. Once assessed, I organized each article based on their most crucial themes as shown on the graph below. Each specific subject was chosen after reviewing the number of times that topic appeared whether in the keywords used or overall discussion of the article. Topics heavily discussed were more prevalent in the overall study but not separated from those that were apparent in smaller amounts.

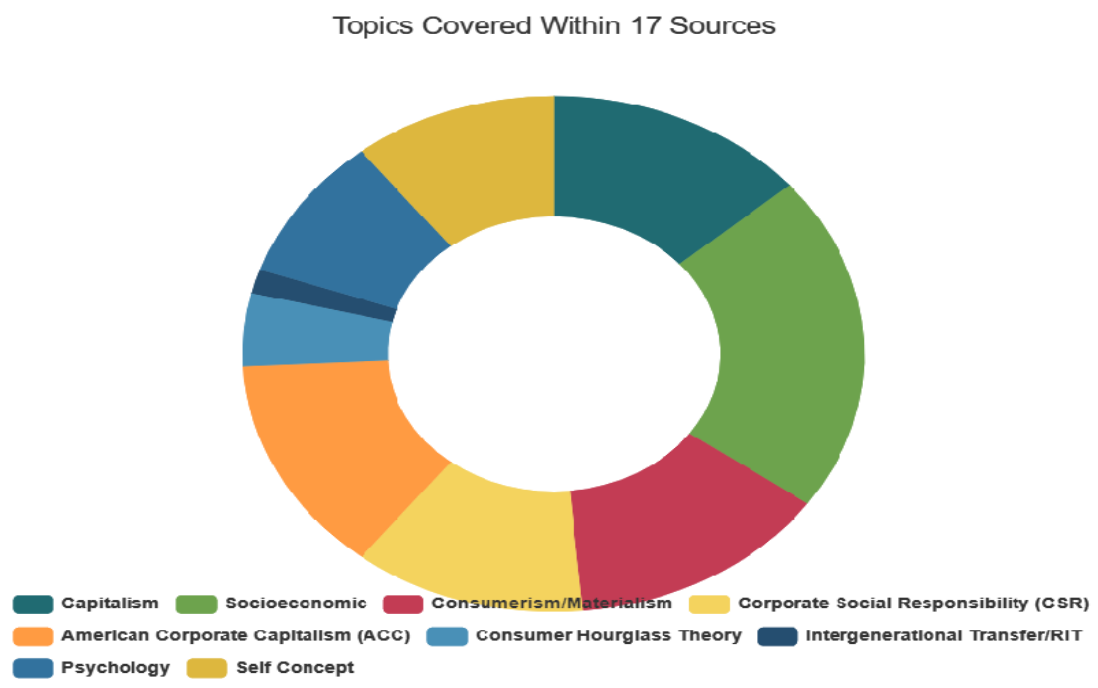

Figure 1. Illustration of Topic Coverage Among Sources 
Articles that were prevalent in multiple arenas offered the best information for application. Many, if not all, of the major premises showed either a neutral or negative relationship between a growing free market and adolescent mental states. Based on those tests involving child consumerist habits, final conclusions were drawn based on their predispositions and the psychological positivity or negativity of such behaviors. During the adolescent stage based on Erikson's Stages of Psychological Development, children are in the process of Identity v. Role Confusion. At this time, they seek understanding as to who they are through practicing various roles and mentalities among their families and peer groups. Juli B. Kramer noted in the "Ethical Analysis and Recommended Action in Response to the Dangers Associated with Youth Consumerism" that while the identity search is occurring, the American Psychological Association (APA) strengthens its capabilities within advertising psychology. Division 23 of the APA is the Society for Consumer Psychology focused on advertising and increasing consumption. Its most key theory is 'Cradle to Grave Loyalty and Consumerism'. Psychologists are hired by companies to publicize their products to the point where children twelve years and older recognize brands as an important cue for purchasing.

With the information gathered, Kramer's study provides excellent insight into the APA's regulations involving proven child inflictions. That paired with the studies and research articles created by nearly all sources listed above allows for a comprehensive analysis of the behavioral changes in adolescents of which American Corporate Capitalism instigates.

\section{Discussion}

\section{Economic Disparities}

The richest one percent of the United States is estimated to own forty percent of the country's wealth, twenty-four percent of the national income, fifty percent of mutual stocks, yet only five percent of the national debt. Due to such financial disparities, companies naturally downsize during good times and flood themselves with workers during stricter periods (George, 2013). This pattern of behavior has surveys indicating that Americans are more likely to believe the poor have opportunities and that their lethargy is the reason for their financial situations (Alesina \& Glaeser, 2004). These beliefs make people more likely to support an escalation of income inequality, layoffs, and other safety nets which cause a ripple effect from the parents laid off to the children depending on them.

Economic factors such as wealth status come into effect when society focuses on constantly upgrading to the next best thing currently available. The issue is, as teens begin to stress for these items, parents often find themselves unable to fund such extravagances. Being unable to obtain such materials places the child against their adults in a battle for monetary gain. (Akee, 2010) noted that with "[a]n additional $\$ 4,000$ per year for the poorest households increases educational attainment by one year at age 21 and reduces having ever committed a minor crime by $22 \%$ at ages 16-17."

Such an influential factor to consumerism, household income can prove a difficult subject when attempting to purchase the next best item on the market. What parents gain in income is turned to focus on the household and familial needs before buying materials unnecessarily. Studies have concluded that there is more conflict between a parent and a child with a materialistic mindset due to such issues monetarily.

\section{Institutional Behaviors}

ACC is indeed like other social systems in which it possesses an ideology that organizes institutions into creation. Adam Smith, the Grandfather of Capitalism, suggests the "pursuit of self-interest through competition provides the best means of ensuring economic growth, happiness, and the good of the community." (Kasser et al., 2007, para. 5). The Schwartz Theory characterizes three levels of conflict which determine the level of ACC effective in businesses. Mastery v. Harmony is the battle between a forceful action of control which dominates social milieu compared to 
having consensus with integration of individuals into their environment via transcendentalism. Hierarchy v. Egalitarianism is the attempt to manage interdependencies with hierarchical relationships as opposed to voluntary cooperation and equality. It is the ideal of wealth and authority challenging justice and honesty. Finally, Embeddedness v. Intellectual Autonomy is the struggle between identifying with collective goals or independence. (S. Schwartz, 1999, 2004) found in their cross-national research that "the more similar the economic system of a capitalist country to ACC, the more its culture is characterized as high in the Mastery, Hierarchy, and Embeddedness orientations..."” (p. 11).

This can be shown with the rising Epipen issue within the United States. In 1996, the average price for the medication was $\$ 21$ but as of 2019 that rose to \$295 per pack. Many families find themselves rationing and searching the black market for cheaper medication to support their children and loved ones afflicted. More importantly, many studies have linked financial performance to corporate social responsibility (CSR).

CSR grows alongside consumer knowledge. In order to gain the favor of the public, it's become a societal expectation to have businesses involved with the community in some fashion. With more people researching their products, companies now tailor themselves to the different dimensions within Corporate Social Responsibility. Companies with emphasis on health and safety, environmental, and biotechnical advancements are more likely to win society's willingness to pay. That willingness and bias often leads to influencing the child's monetary habits. As noted by (Polacheck 1989), it has often been a wide belief that intergenerational transfer exists where a parent's buying practices are transferred to their children. However, their study also proved that Reverse Intergenerational Transfer exists where the child's evolved purchasing practices change that of their parents. In fact, an indirect test proved having more education acts like having more income (Michael, 1972).

Advertise psychology relies on the societal functions of a fast paced free-market society to ensure interaction with the products. This can especially be seen by the usage of sexual stimulation and stereotypes in many popular adult advertisements. It is a popular belief that if given a positive stimulus to a product, the buyer will have more positive relations to buying it (Vlasceanu, 2013). Knowing businesses would cater towards adolescents, the APA had a specific division made strictly for aiding in proper implementation. However, there was severe failure with implementation. Division 23 of the APA is the Society for Consumer Psychology. Five main principles focus on providing trust, accuracy, nonmaleficence, and dignity in allowing people to combat intrusiveness. Yet, Standard 8.07 allows the use of deception which provides increased concerns on the conflict with Standard 3.04 in avoiding harm. This conflict has many encouraging the usage of counter advertising.

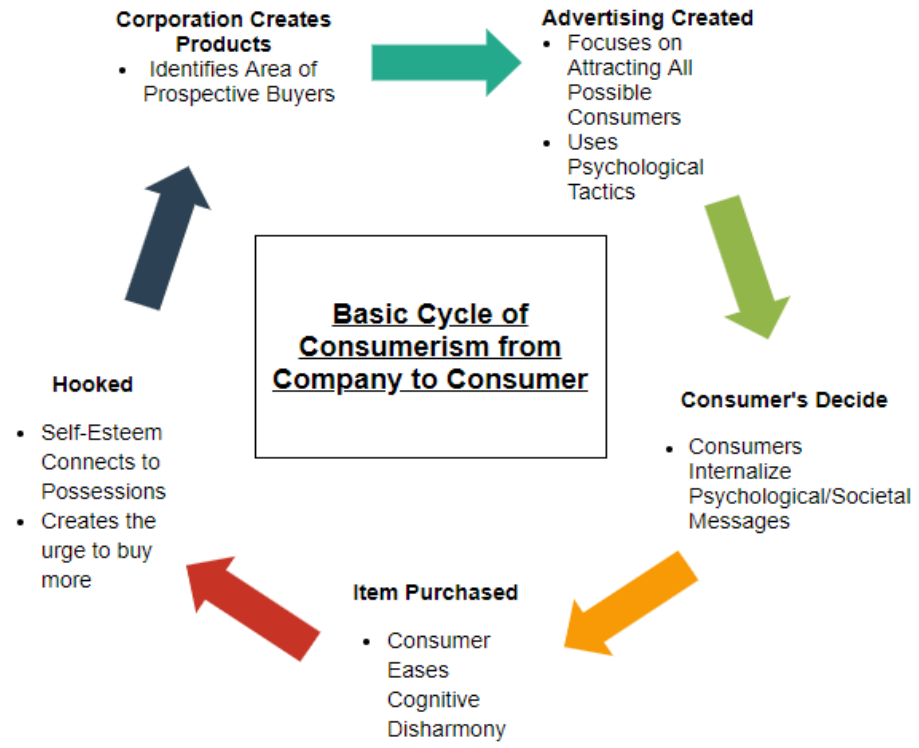

Figure 2. Illustration of Corporate Advertising Strategy 


\section{Child Behaviors}

Materialism becomes an obsessive compulsion to which the individual is either trapped willingly or faces cognitive disharmony attempting to break the pattern. As social norms are built around consumerism, messages of such become internalized; the Id, Freud's term for all unconscious desires and impulses, builds off of such messages until it becomes a founding part of the individual's identity. It is important to note that the level of consumerist habits is foretold based on social, cultural, psychological, and economic factors. In the United States, children in higher socioeconomic status have been shown to focus more on possessing popular brand items and new accessories, tying those to their self-worth.

Research identified a correlation between psychosomatic symptoms of depression, anxiety, and low selfesteem to that of consumerism levels. (Sweeting et al., 2012) explored the findings of multiple studies across the United Kingdom involving adolescent dignity and worth. These studies found highly reported emotional and behavioral issues in eleven to nineteen-year old. Nine to thirteen-year old showed higher parent-child conflict and disappointment as well. Two studies done in the United States by Chaplin and John (2007) recorded the level of consumerism relative to changes in age. The first study found consumerism rising during mid-childhood to early adolescence and lowering towards the latter years of adolescence; the second study identified higher levels of self-esteem induced by the level of materialism evident in the child to the point where age didn't matter.

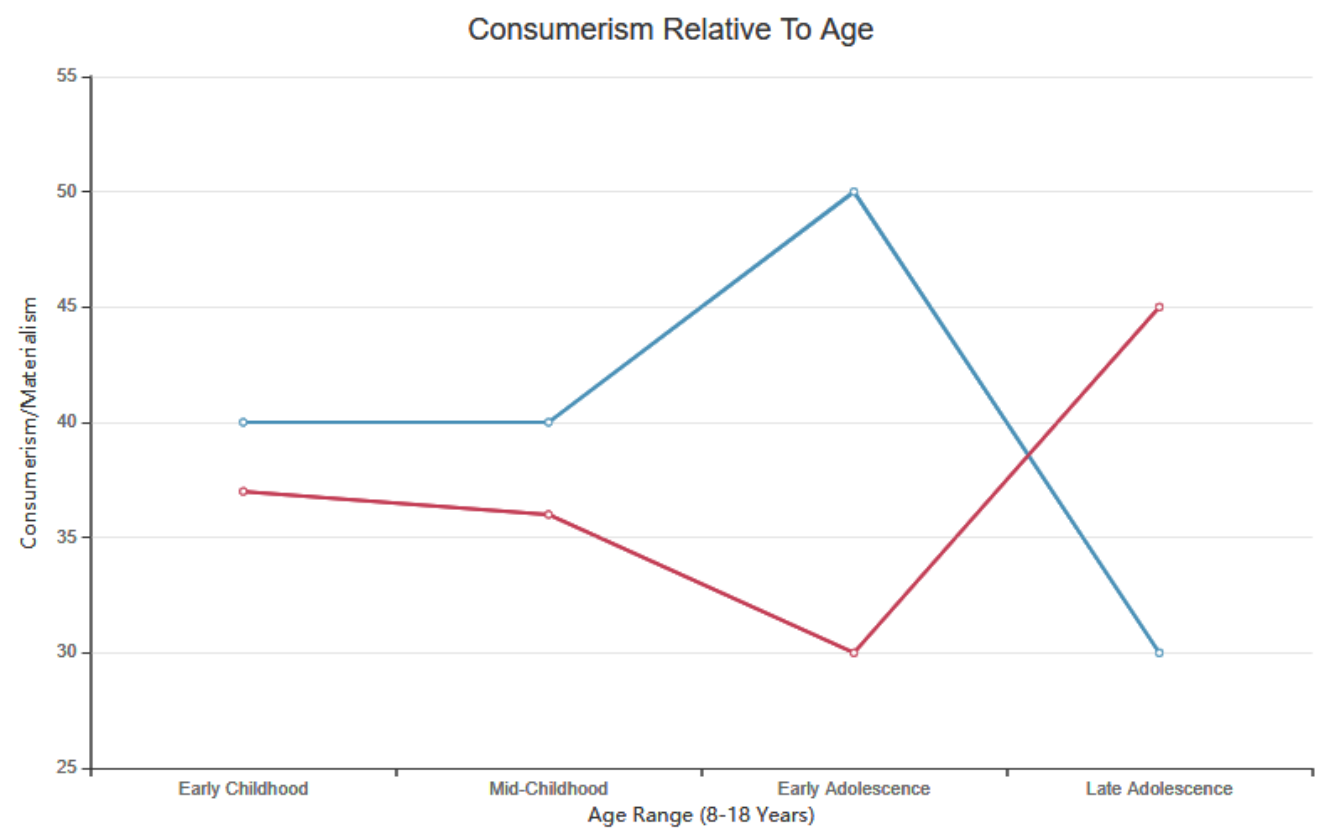

Figure 3. Illustration of Consumerism and Age Correlation

These studies suggest that business theories do influence child outlooks. Though many adolescents today are familiar with the tactics imposed on advertisements and product sales, these ideals are still highly determinate factors of behavior. (Kramer, 2006) perfectly states this finding that "by the time children reach 12 years of age they use brand names as an important conceptual cue in consumer judgement." Utilizing neuropsychology to create strategies aimed at the pathos of children has started notably since James Watson during World War One and continues to be used today. The conflict bred from this is how young children don't have the knowledge nor capability to combat intrusive advertisements. Only reaching adolescence do teenagers begin to increase awareness on what advertisements are purposefully attempting to do. Regardless, a finalized perception regarding the market has been solidified and adolescents now find themselves battling cognitive disharmony in an attempt to ignore marketing practices. 


\section{Conclusion}

This research aimed to identify how the psychology of ACC has affected children ages thirteen to seventeen in the past decade regarding their psychological behavioral changes. Through a content and meta-analysis of multiple sources, I was able to identify the strategies used within ACC culture as well as ACC's impact on the social behaviors of Americans. By taking what I've gathered here, I developed a meta analytical study on how child psychology fairs with the influences of ACC. From these findings, it is evident that adolescents 13-17 years of age face more temptations with consumerist tendencies. Those tendencies present a strong causal factor into low self-esteem and poor mental health habits. Through societal norms integrating with the advertisement processes of businesses, children have become assimilated to the ideas of ACC inherently, making them more prone to these tendencies. Future research could be found as to how adolescents identify and/or rebel against these ideals. It would also be crucial to identify the moral changes within American Corporate Capitalism knowing its relation to child psychosis. As of now, the effects on behavioral changes in children has become increasingly noted due to the influx of advertising.

\section{Acknowledgements}

The research on "American Corporate Capitalism's Effect on Adolescent Psychology" was done in conjunction with the College Board AP Research curriculum as part of my AP Capstone Certification. It is not without the scholarly guidance and assistance from my advisor, Mrs. Diane Patterson that I would have been able to properly complete this project. With honest encouragements and nudges to further my research, she has allowed me to surpass what I had thought I would be able to accomplish at the beginning of this undertaking. I find it also necessary to thank the Northridge STEM Academy itself for providing the tools and sources for such research. It would be foolish not to also thank those before me who found much vital information that would come of use in the final makings of my research. With this combination of aid, I was able to produce a work I am proud of with the highest appreciation for those involved.

\section{References}

Sweeting, H., Hunt, K., \& Bhaskar, A. (2012). Consumerism and well-being in early adolescence. Journal of Youth Studies, 15(6), 802-820. https://doi.org/10.1080/13676261.2012.685706

Kasser, T., Cohn, S., Kanner, A., \& Ryan, R. (2007). TARGET ARTICLE: Some Costs of American Corporate Capitalism: A Psychological Exploration of Value and Goal Conflicts. Psychological Inquiry, 18(1), 1-22. https://doi.org/10.1080/10478400701386579

Hickey, R. (2014). When the Desire to Do Good Makes You Feel Bad: Quality Indicators and Worker Stress. Journal on Developmental Disabilities, 20(2), 78-88. Retrieved from http://search.ebscohost.com/login.aspx?di$\underline{\text { rect }=\text { true } \& \mathrm{db}=\mathrm{asn} \& \mathrm{AN}=98571644 \& \text { site }=\text { ehost-live }}$

Durant, R. F. (2013). Progressivism, Corporate Capitalism, and the Social Sciences. Administration \& Society, 46(6), 599-631. doi: 10.1177/0095399713509244

Polachek, D. E., \& Polachek, S. W. (1989). An Indirect Test of Children's Influence on Efficiencies in Parental Consumer Behavior. Journal of Consumer Affairs, 23(1), 91. https://doi.org/10.1111/j.1745-6606.1989.tb00237.x 
George, J. M. (2014). Compassion and Capitalism: Implications for Organizational Studies. Journal of Management, 40(1), 5-15. https://doi.org/10.1177/0149206313490028

Sweeting, H., Hunt, K., \& Bhaskar, A. (2012). Consumerism and well-being in early adolescence. Journal of Youth Studies, 15(6), 802-820. https://doi.org/10.1080/13676261.2012.685706

Kramer, J. B. (2006). Ethical Analysis and Recommended Action in Response to the Dangers Associated With Youth Consumerism. Ethics \& Behavior, 16(4), 291-303. https://doi.org/10.1207/s15327019eb1604 2

Myers, G. D. (2007). Costs and Benefits of American Corporate Capitalism. Psychological Inquiry, 18(1), 43-47. https://www.jstor.org/stable/20447354

Whybrow, P. (2007). COMMENTARIES: Adam Smith's American Dream: Time to Take Stock. Psychological Inquiry, 18(1), 57-59. https://doi.org/10.1080/10478400701389003

Collins, M. (2015, August 4). The Winners And Losers Of Free Market Capitalism. Retrieved October 13, 2019, Retrieved from https://www.forbes.com/sites/mikecollins/2015/08/04/the-winners-and-losers-of-free-market-capital$\underline{\text { ism/\#2f8c15ff7f75 }}$

VLĂSCEANU, S. (2013). Psychology of the Consumer's and the Advertise in Terms of Factors That Leads to Consumer's Decision Making. Romanian Journal of Experimental Applied Psychology, 4(1), 23-28. Retrieved from http://search.ebscohost.com/login.aspx?direct=true\&db=asn\&AN=94646556\&site=ehost-live

Kinni, T. (2017, September 18). Is Capitalism Killing America? Retrieved October 1, 2019, from https://www.gsb.stanford.edu/insights/capitalism-killing-america

Kumar K, Boesso G, Batra R, Yao J. Explicit and implicit corporate social responsibility: Differences in the approach to stakeholder engagement activities of U.S. and Japanese companies. Bus Strat Env. 2019;1-10. https://doi.org/10.1002/bse.2306

Northwestern Business Review. (2017, March 22). Why Citi's Consumer Hourglass Theory Matters. Retrieved from https://northwesternbusinessreview.org/why-citis-consumer-hourglass-theory-matters-3a2c1e9345c9

Akee, R. K., Copeland, W. E., Keeler, G., Angold, A., \& Costello, E. J. (2010). Parents' Incomes and Children's Outcomes: A Quasi-Experiment. American economic journal. Applied economics, 2(1), 86-115. https://doi.org/10.1257/app.2.1.86

Schneirov, M., \& Schneirov, R. (2016). Capitalism as a social movement: the corporate and neoliberal reconstructions of the American political economy in the twentieth century. Social Movement Studies, 15(6), 561-576. https://doi.org/10.1080/14742837.2016.1215242

Chaplin, L. N., \& John, D. R. (2007). Growing up in a material world: Age differences in materialism in children and adolescents. Journal of consumer research, 34(4), 480-493. 